\title{
Clinical and Ultrasonographic Studies in Bovine Respiratory Disease (BRD) Affected Calves
}

\author{
Eman Abdelhakim Ahmed ${ }^{1}$, Asmaa, O. Ali ${ }^{1}$, Abdelaal, A. M. ${ }^{2}$ \\ and *Mahmoud A. El-Sayed ${ }^{1}$. \\ 1 Department of Animal Medicine, Faculty of Veterinary Medicine \\ Suez Canal University, Ismailia, Egypt. 41522 \\ 2 Department of Animal Medicine, Faculty of Veterinary Medicine \\ Zagazig University, Sharkia, Egypt. 44519
}

\author{
*Corresponding author: Mahmoud A. El-Sayed \\ ahmedvet_2012@yahoo.com
}

\section{Abstract}

Bovine Respiratory Diseases (BRD) are one of the most common and important disease problem affecting newborn calves. The aim of this study was to use clinical respiratory score and thoracic ultrasonography as a screening method for diagnosis BRD in newborn calves. This study was carried out on 59 newborn calves in Al-salhia farm for investment in Alsharqia Governorate, Egypt. These calves were divided into two groups. The first group (G1) including 16 healthy control calves and the second group (G2) including 43 newborn calves suffered from respiratory disorders. The most prominent clinical finding in BRD affected calves were fever, nasal and ocular discharge, coughing with abnormal tracheal and lung sounds. According to ultrasonographic examination of lung, the lower respiratory tract disorders classified lesion into lobar pneumonia 12 calves (35.3\%), lobular pneumonia 16 calves (47.1\%), mixed pneumonia 3 calves $(8.82 \%)$ in addition to lung abscess 3 calves (8.82\%). Clinical respiratory score and thoracic ultrasound score showed a highly significant increase in BRD affected calves, meanwhile CRS showed a nonsignificant change in calves suffered from upper and lower respiratory tract disorders. TUS revealed a non- significant change in calves with lobar and mixed pneumonia and in lung abscess, in addition to a significant increase in calves with lobar pneumonia when compared with lobular pneumonia. BRD affected calves had CRS $\geq$ five meanwhile calves with TUS $\geq$ two were considered sick.

Key words: BRD, Clinical respiratory score, Thoracic ultrasonography score. 


\section{Introduction}

Bovine Respiratory Disease (BRD) is one of the most common and important disease problems in calves. It is a complex inflammatory disease caused by pathogenic and opportunistic viruses and bacteria in case of adverse environmental conditions and impairment of calves' immunity (Hägglund et al., 2006).

BRD causes major economic losses in both production systems. This disease is predominantly associated with young calves, heifers and steers starting from the first weeks of life Orro (2008). Furthermore, Buczinski et al. (2013) reported that BRD in dairy calves and its consequences are associated with increased costs of rearing, increased risks of mortality or relapses, as well as impaired growth and early culling.

Cramer and Ollivett (2019) stated that BRD accounts for approximately $23 \%$ of heifer deaths during the preweaning period. Other short-term consequences of preweaning BRD include increased treatment costs and reduced growth. The long-term effects of preweaning BRD include decreased survival to first calving.

Griffin et al. (2010) and ElSheikh et al. $(2020, B)$ stated that the most common signs of
BRD are fever, depression, decreased appetite, nasal and ocular discharges, coughing, varying degrees of breathing difficulty and noise, rapid breathing, droopy ears, open mouthed breathing and death. These vary greatly, depending on the stage and extent of the disease process.

McGuirk (2008) stated that a clinical respiratory score (CRS) improves early detection, provides more reliable information on case rate, monitors for treatment efficacy and determines which calves can move into the post weaning group pen. Beside that Buczinski et al. (2014) reported that clinical score has been widely used as a practical tool for calf ranchers when screening calves for acute BRD in addition. The CRS was designed to focus on early diagnosis of BRD with typical clinical signs that can be easily implemented on dairy farms.

Thoracic ultrasonography (TU) considered as non - invasive assessment of lung parenchyma and has a valuable tool to monitor thoracic lesions associated with pneumonia and pleuritis. It can be done quickly calf-side and gives an immediate result. For these reasons, it could be potentially useful in the field when examining a calf with suspected BRD, and as a 
research tool when monitoring subclinical BRD, especially focusing on the extent of lung consolidation (Buczinski et al., 2014).

Glover (2017) reported that pulmonary ultrasound may be useful as a means of detecting calves in the early stages of disease prior to development of other clinical signs, or of detecting subclinical cases, in order to initiate metaphylaxis. In addition, it may aid in assessment of the extend of recovery following treatment. Therefore, the aim of this study was to evaluate severity of signs of BRD affected calves through estimation of clinical respiratory score (CRS) and thoracic ultrasonographic score (TUS).

\section{Materials and Methods \\ Ethical approval}

All procedures used in the present study were approved by the Scientific Research Ethics Committee on animal researches, Faculty of Veterinary Medicine, Suez Canal University, Egypt.

\section{Animal and study design}

The present study was carried out on ninety-five (59) Holstein dairy calves (24 males and 35 females) from 30 day of age until weaning. Calves were reared in Al-Salhya Dairy Farm, Alsharqaia Governorate, Egypt, during the period of December 2019 till March 2020. Calves were classified according to CRS and TUS into three groups: the $1^{\text {st }}$ group (G1): consist of 16 apparent healthy newborn calves, the $2^{\text {nd }}$ group (G2): consist of 9 newborn calves suffering from upper respiratory tract affection, the $3^{\text {rd }}$ group (G3): consist of 34 newborn calves suffering from lower respiratory tract affection.

All calves were housed in a group hutch on open yard. Calves were fed on 3 meals of milk per day at a rate of 2-3 liters $/ \mathrm{mea} / \mathrm{calf}$ and during these periods the calf starter (Table 1) and tap water were available $a d$ libtum.

\section{Clinical examination}

Detailed physical examination of respiratory system was carried according to clinical procedure cited by Nagy et al. (2006) depending on the criteria of clinical assessment. These criteria included behavior, mental status, body temperature, body condition, inspection of breathing, nasal discharge, dyspnea, coughing, additional respiratory movements by auscultation of the trachea and lungs which include type, character and intensity of breath sounds in addition to adventitious respiratory sounds.

\section{Clinical respiratory score}

\section{(CRS)}

Clinical respiratory score (CRS) was carried for each individual calf according to Love et al., 
(2014) based on rectal consolidated, score 4 means temperature, characters of nasal discharge, ocular discharge, presence of cough and ear position as shown in table (2). This score is the sum of points obtained from these clinical signs that ranged from zero to 15 , which predict progressive severity with the increased score. Calves with score four or higher had at least three clinical signs and considered diseased and included in this study.

\section{Thoracic ultrasound scoring} (TUS)

Ultrasonographic examinations were performed using a portable linear transducer, approximately $300 \mathrm{~mL}$ of $70 \%$ isopropyl alcohol was applied to the hair as the transducing agent without shaving of hair. Systematic scanning of chest was carried out according to procedure cited by (Ollivett et al., 2015),

Cramer and Ollivett (2019) reported that for the thoracic ultrasound scoring (TUS), five lung lobes in total were examined and considered separate lung lobes for the scoring system. The TUS ranged from zero to 5 including six points, zero means normal or the consolidated area less than 1 $\mathrm{cm} 2$, score 1 means presence of diffuse comet tails, score 2 means lobular pneumonia where the consolidated area $\geq 1 \mathrm{~cm} 2$, score 3 means lobar pneumonia, which has 1 entire lung lobe

lobar pneumonia which has 2 entire lung lobes consolidated. Meanwhile, score 5 means lobar pneumonia which has $\geq 3$ entire lung lobes consolidated as shown in table (3).

\section{Statistical analysis}

The data were analyzed statistically using one-way analysis of variance (ANOVA) by using SPSS program (version, 20). The difference was considered significant if $\mathrm{P} \leq$ 0.05 .

\section{Result: \\ A total number of 43 dairy calves represent $25.6 \%$ (43/168) were suffered from clinical respiratory disorders selected from all calves in the farm. The diseased calves were selected on the basis of obvious clinical findings appeared on the calves.}

\section{Clinical findings :}

Clinical examination of apparently healthy calves revealed a normal body temperature in average of $38.6 \mathrm{C}^{\circ}$, non or scanty serous nasal discharge and normal tracheal and vesicular sound. Meanwhile, fever, nasal discharge, ocular discharge, coughing and abnormal lung sounds were the main clinical signs recorded in BRD affected calves.

In case of upper respiratory tract disorders $(N=9)$, the dairy calves recorded an elevation of 
body temperature up to $39.7 \mathrm{C}^{\circ}$, general depression and weakness. The nasal discharge was unilateral seromucoid and bilateral mucoid in other cases. Spontaneous and or induced, single cough was observed. Unilateral or bilateral serous or seromucoid ocular discharge was noticed in some cases. Examination of the trachea revealed exaggerated tracheal sound that accompanied with rattling and/ or stenotic sound. Auscultation of the chest revealed normal vesicular sound. Calves suffered from lower respiratory tract disorders $(N=34)$ as pneumonic cases were accompanied with weakness, some cases recorded an elevation of body temperature up to 40.5 $\mathrm{C}^{\circ}$, increased degree of bilateral mucopurulent nasal and bilateral ocular discharge, Polypnea, moist paroxysmal coughing, and severe dyspnoea as shown in picture (1 and 2). Examination of the trachea revealed presence of rattling meanwhile auscultation of the chest revealed presence of severe crackles and wheezes that occupied large area of the affected lobe.

Clinical respiratory score and thoracic ultrasonographic score:

A highly significant increase in the mean values of CRS and TUS at $(\mathrm{P} \leq 0.01)$ was recorded in BRD affected calves compared with the control group (Table, 4 and figure 1).

Based on the result of CRS and TUS, BRD affected calves were further classified into upper respiratory disorders 9 calves (20.9\%), and lower respiratory disorders 34 calves $(79.1 \%)$ as showed in Table (5).

A significant increase in the mean values of $\mathrm{CRS}$ at $(\mathrm{P} \leq 0.05)$ of calves with upper and lower respiratory tract disorders compared with the control group, and a non-significant change was observed in the mean values of upper respiratory tract disorders compared with lower respiratory tract disorders. In addition, a significant increase in the mean values of TUS at $(\mathrm{P} \leq$ 0.05 ) of calves with lower respiratory tract disorders compared with the control group and upper respiratory tract disorders. Meanwhile, a nonsignificant change in mean values of TUS at $(\mathrm{P} \leq 0.05)$ was recorded in calves with upper respiratory tract disorders compared with control group (Table, 5 and figure, 2).

The lower respiratory tract disorders were further classified according to ultrasonographic lesion into lobar pneumonia 12 calves $(35.3 \%)$ with Full thickness consolidation of the lung lobe as shown in picture (3), lobular pneumonia 16 calves $(47.1 \%)$ with relatively small discreet areas of consolidation as 
shown in picture (4), mixed pneumonia 3 calves $(8.82 \%)$ in addition to lung abscess 3 calves $(8.82 \%)$ with hypo echoic circumscribed structure surrounded by echogenic wall as shown in picture (5) and table (6).

A highly significant increase in the mean values of CRS and TUS at $(\mathrm{P} \leq 0.05)$ was recorded in calves with lobar pneumonia, lobular pneumonia, mixed pneumonia and lung abscess compared with the control group, Meanwhile, a nonsignificant changes in the mean values of $\mathrm{CRS}$ at $(\mathrm{P} \leq 0.05)$ were recorded in calves with lobar pneumonia, lobular pneumonia and lung abscess, in addition to a highly significant increase in the mean values of $\mathrm{CRS}$ at $(\mathrm{P} \leq 0.05)$ was recorded in calves with lobar pneumonia compared with mixed pneumonia and a nonsignificant change in the mean values of $\mathrm{CRS}$ at $(\mathrm{P} \leq 0.05)$ in calves with mixed pneumonia and lung abscess (Table, 6 and Figure, 3).

A non- significant change in the mean values of TUS at $(\mathrm{P} \leq$ $0.05)$ in calves with lobar pneumonia, mixed pneumonia and lung abscess, in addition to high significant in mean values of TUS at $(\mathrm{P} \leq 0.05)$ in calves with lobar pneumonia and lobular pneumonia (Table, 6 and figure, 3).

Table (1): Ingredient and chemical composition of calf starter ration.

\begin{tabular}{|l|c|}
\hline \multicolumn{1}{|c|}{ Ingredients } & Percent \\
\hline Ingredient (\%, asfed basis) & 52.5 \\
\hline Maize grain & 17 \\
\hline Corn gluten feed & 28 \\
\hline Soybean meal44\% protein & 1 \\
\hline Limestone powder & 0.5 \\
\hline Iodized sodiumchloride & 1 \\
\hline Trace mineral and vitamin premix & 100 \\
\hline Total & 88.43 \\
\hline Chemical composition (on DM basis) & 18.2 \\
\hline Dry matter(\%) & 3.41 \\
\hline Crude protein (\%) & 3.87 \\
\hline Ether extract (\%) & 2.66 \\
\hline Crude fiber(\%) & 3.04 \\
\hline Ash (\%) & 59.86 \\
\hline Metabolizable energy, Mcal/kg & $2: 1$ \\
\hline Protein energy ratio, g/Mcal & \\
\hline Ca:P ratio & \\
\hline
\end{tabular}

* Each kilogram of trace mineral and vitamin premix contains: vitamin A (50,000 IU); vitamin D3 (10,000IU); vitamin E (0.1 g); calcium (196 g); phosphorus (96 g); sodium (71 $\mathrm{g}$ ); magnesium sulphate (19 $\mathrm{g})$; iron sulphate $(3 \mathrm{~g})$; copper sulphate( 0.3 
g); manganese ( $2 \mathrm{~g})$; zinc sulphate ( $3 \mathrm{~g})$; cobalt sulphate $(0.1 \mathrm{~g})$; potassium iodide $(0.1 \mathrm{~g})$; sodium selenate $(0.001 \mathrm{~g})$.

* Nutrientanalysis according to A.O.A.C (2001).

Table (2): Clinical respiratory scoring Chart

\begin{tabular}{|c|c|c|c|c|}
\hline $\begin{array}{c}\text { Degree } \\
\text { Criteria }\end{array}$ & 0 (Normal) & $\begin{array}{c}1 \\
\text { (Mild) }\end{array}$ & $\begin{array}{c}2 \\
\text { (Moderate) }\end{array}$ & $\begin{array}{c}3 \\
\text { (Severe) }\end{array}$ \\
\hline Temperature & $37.7-38.2$ & $\mathbf{3 8 . 3 - 3 8 . 8}$ & $\mathbf{3 8 . 8 - 3 9 . 3}$ & $\geq 39.3$ \\
\hline Nasal discharge & $\begin{array}{c}\text { Scanty } \\
\text { serous } \\
\text { discharge } \\
\text { Ocular } \\
\text { discharge }\end{array}$ & $\begin{array}{c}\text { Small } \\
\text { unilateral } \\
\text { cloudy } \\
\text { discharge }\end{array}$ & $\begin{array}{c}\text { Bilateral } \\
\text { cloudy or } \\
\text { excessive } \\
\text { mucous }\end{array}$ & $\begin{array}{c}\text { Copious bilateral } \\
\text { mucopurulent }\end{array}$ \\
\hline discharge & $\begin{array}{c}\text { Small } \\
\text { omount of } \\
\text { discharge }\end{array}$ & $\begin{array}{c}\text { Moderate } \\
\text { bilateral ocular } \\
\text { discharge }\end{array}$ & $\begin{array}{c}\text { Copious ocular } \\
\text { discharge }\end{array}$ \\
\hline Cough & No cough & $\begin{array}{c}\text { Induced } \\
\text { single }\end{array}$ & $\begin{array}{c}\text { Induced } \\
\text { repeated or } \\
\text { occasional } \\
\text { spontaneous }\end{array}$ & $\begin{array}{c}\text { Repeated } \\
\text { spontaneous }\end{array}$ \\
\hline $\begin{array}{c}\text { Ear and head } \\
\text { position }\end{array}$ & Normal & $\begin{array}{c}\text { Ear flick or } \\
\text { headshake }\end{array}$ & $\begin{array}{c}\text { Slight } \\
\text { unilateral } \\
\text { droop }\end{array}$ & $\begin{array}{c}\text { Head tilt or } \\
\text { bilateral droop }\end{array}$ \\
\hline
\end{tabular}

Table (3): Thoracic ultrasound scoring chart

\begin{tabular}{|c|c|c|}
\hline TUS & Description & Judgment \\
\hline 0 & Normal or $<1 \mathrm{~cm} 2$ consolidation & Normal \\
\hline 1 & Diffuse comet tails & Normal \\
\hline 2 & consolidation $\geq 1 \mathrm{~cm} 2$ & Lobular pneumonia \\
\hline 3 & 1 entire lung lobe consolidated & Lobar pneumonia \\
\hline 4 & 2 entire lung lobes consolidated & Lobar pneumonia \\
\hline 5 & $\geq 3$ entire lung lobes consolidated & Lobar pneumonia \\
\hline
\end{tabular}

Table (4): The mean values \pm S. E of CRS and TUS in diseased dairy calves compared with control group.

\begin{tabular}{|c|c|c|}
\hline Groups & Control (16) & Diseased(43) \\
\hline CRS & $2.4^{\mathrm{b}} \pm 0.17$ & $6.02^{\mathrm{a}} \pm 0.19$ \\
\hline TUS & $0.38^{\mathrm{b}} \pm 0.12$ & $2.63^{\mathrm{a}} \pm 0.25$ \\
\hline
\end{tabular}

Means carrying different superscripts in the same row are significantly different at $\quad(P \leq 0.05)$ or highly significantly different at $(P<0.01)$.

Means carrying the same superscripts in the same row are nonsignificantly different at $(P>0.05)$. 
Table (5): The mean values \pm S.E of CRS and TUS in upper and lower respiratory tract disorders compared with control group.

\begin{tabular}{|c|c|c|c|}
\hline Groups & Control (16) & $\begin{array}{c}\text { Upper } \\
\text { respiratory } \\
\text { tract disorders } \\
(\mathbf{9})\end{array}$ & $\begin{array}{c}\text { Lower } \\
\text { respiratory } \\
\text { tract disorders } \\
\mathbf{( 3 4 )}\end{array}$ \\
\hline CRS & $2.4^{\mathrm{b}} \pm 0.17$ & $5.77^{\mathrm{a}} \pm 0.14$ & $6.03^{\mathrm{a}} \pm 0.25$ \\
\hline TUS & $0.38^{\mathrm{b}} \pm 0.12$ & $0.33^{\mathrm{b}} \pm 0.16$ & $3.24^{\mathrm{a}} \pm 0.22$ \\
\hline
\end{tabular}

Means carrying different superscripts in the same row are significantly different at $\quad(P \leq 0.05)$ or highly significantly differentat $(P<0.01)$.

Means carrying the same superscripts in the same row are nonsignificantly different at $(P>0.05)$.

Table (6): The mean values \pm S.E of CRS and TUS in lower respiratory tract disorders compared with control group.

\begin{tabular}{|c|c|c|}
\hline Items Groups & CRS & TUS \\
\hline Control & $2.4^{\mathrm{c}} \pm 0.17$ & $0.38^{\mathrm{c}} \pm 0.12$ \\
\hline Lobar pneumonia & $6.75^{\mathrm{a}} \pm 0.49$ & $4.17^{\mathrm{a}} \pm 0.23$ \\
\hline Lobular pneumonia & $5.56^{\mathrm{ab}} \pm 0.26$ & $2.0^{\mathrm{b}} \pm 0.0$ \\
\hline Mixed pneumonia & $4.67^{\mathrm{b}} \pm 0.27$ & $4.33^{\mathrm{a}} \pm 0.27$ \\
\hline Lung abscess & $6.67^{\mathrm{a}} \pm 0.14$ & $4.67^{\mathrm{a}} \pm 0.0$ \\
\hline
\end{tabular}

Means carrying different superscripts in the same columare significantly different at $(P \leq 0.05)$ or highly significantly different at $(P<0.01)$.

Means carrying the same superscripts in the same colum are nonsignificantly different at $(P>0.05)$. 


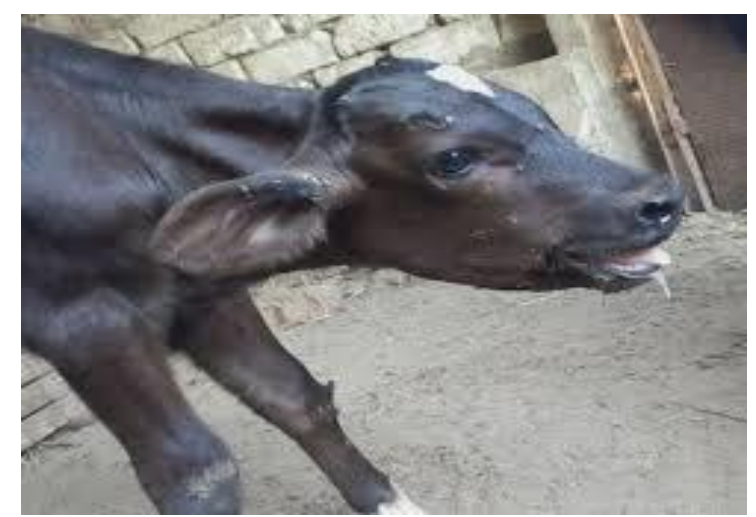

Picture (1): Dyspnea in newly born dairy calves suffered from acute pneumonia.

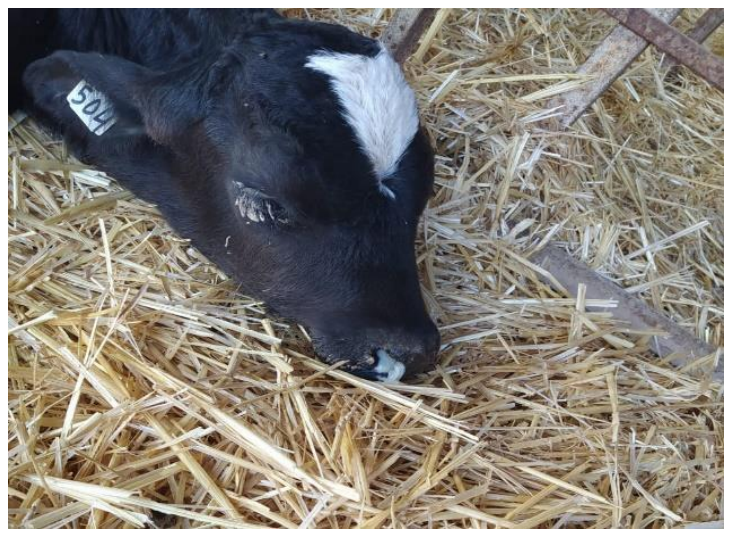

Picture (2): Copious bilateral mисорurulent nasal discharge in newly born dairy calves suffered from pneumonia.

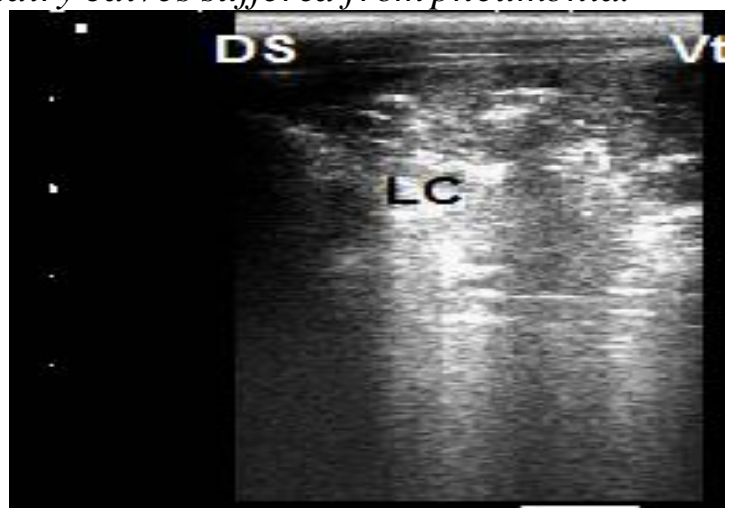

Picture (3): thoracic ultrasound oflobar pneumonia with hyper echoic structure (lung consolidation) of all middle lobe of right lung (right), linear probe placed on 5 ICS, hyper echoic structure of all cranial lobe of left lung (left), linear probe placed on 2-3 ICS. Ds; dorsal, Vt; ventral, TW; thoracic wall, LC; lung consolidation. 


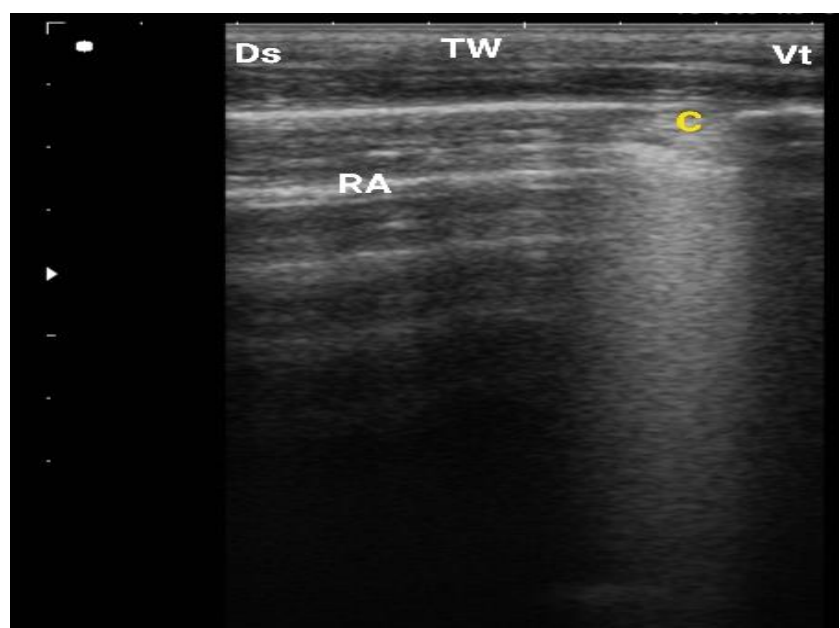

Picture (4): thoracic ultrasound of lobular pneumonia with $1 \mathrm{~cm}$ consolidation in ventral of cranial lobe of left lung linear probe placed on 3 ICS with reverbration artifact.

$D s$; dorsal, Vt; ventral, TW; thoracic wall, C; consolidation, $R A$; reverbration artifact.
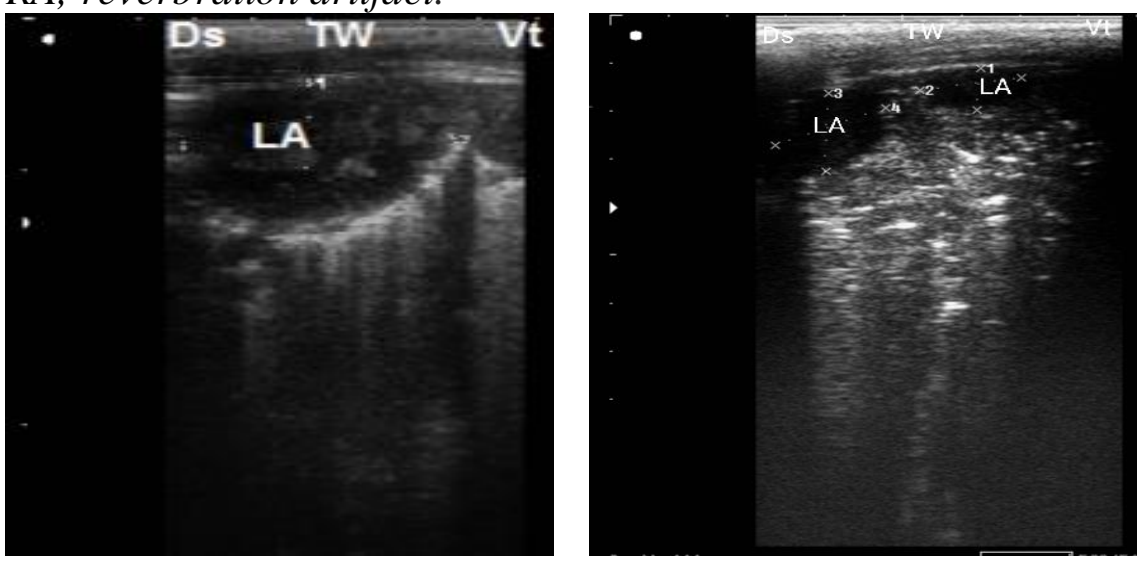

Picture (5): Thoracic ultrasound of lung abscess with hypo echoic circumscribed structure surrounded by echogenic wall appeared within lung tissues. Right; multiple small sized abscess in cranial lobe of left lung sized $1 \times 2 \mathrm{~cm}$, linear probe placed on 2-3 ICS. Left; single large abscess in cranial lobe of right lung sized $3 \times 4 \mathrm{~cm}$, linear probe placed on 1-4 ICS. 


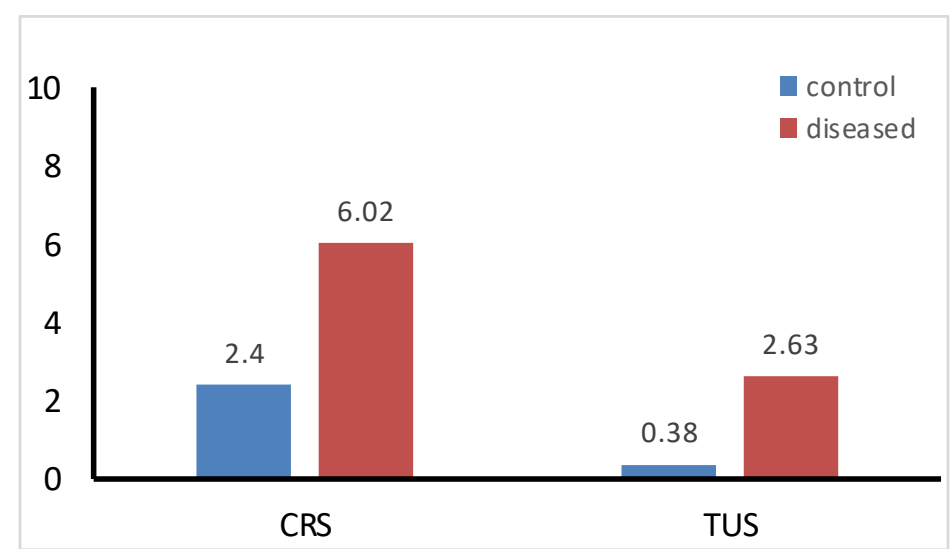

Figure (1): The mean values \pm S.E of CRS and TUS in diseased dairy calves compared with control group.

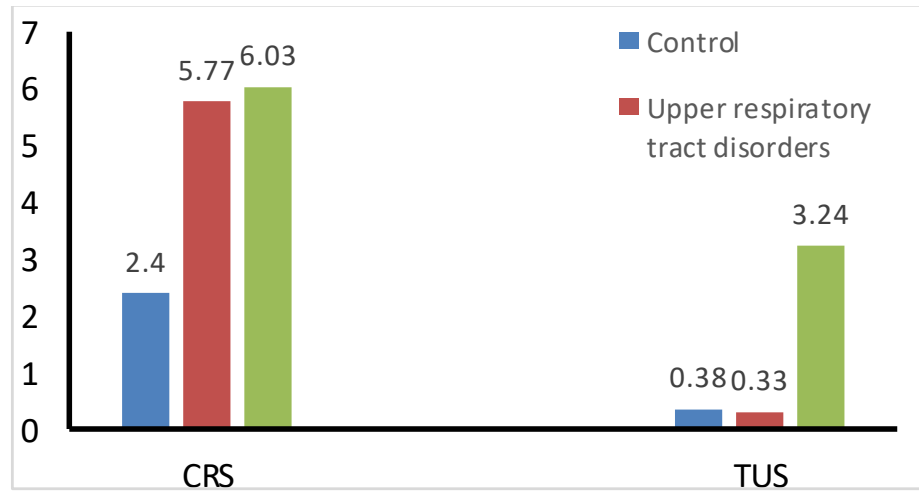

Figure (2): The mean values \pm S.E of CRS and TUS in upper and lower respiratory tract disorders compared with control group.

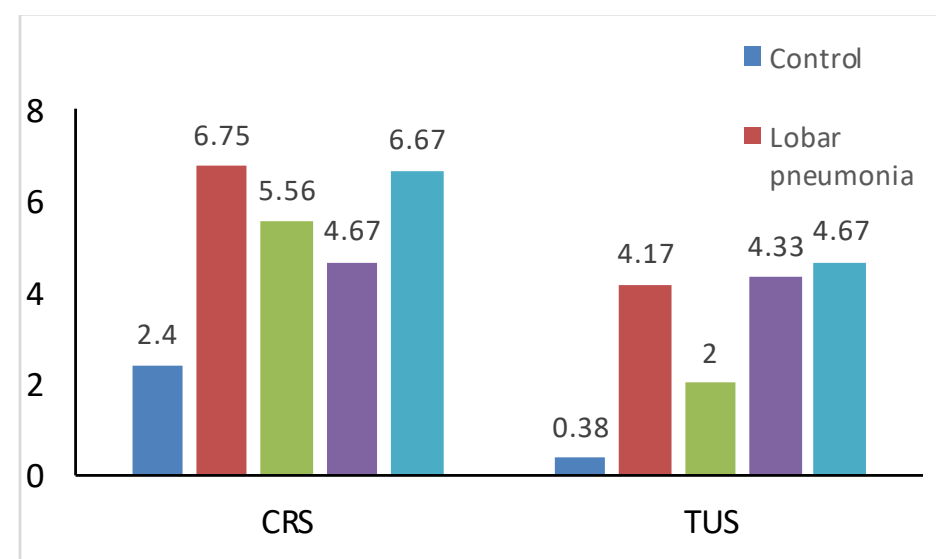

Figure (3): The mean values \pm S.E of CRS and TUS in lower respiratory tract disorders compared with control group. 


\section{Discussion}

\section{Clinical findings:}

The major clinical findings observed in the BRD affected calves were attributed to bad ventilation, poor immunity, high stocking density and close contact between diseased and healthy calves as mentioned by (Abd El-latif, 2011).

Elevated body temperature in diseased calves could be attributed to the pyrogenic effect of cytokines caused by pyrogenic microbes as interleukin (IL-1 and IL-6) and TNF- $\alpha$ that reach brain through circulation resulting in elevation of body temperature through prostaglandin mediated mechanism as mentioned by (Constable et al., 2016).

The nasal discharge in all diseased calves mostly was mucoid and mucopurulent and could be ascribed to stimulation of the goblet cells by inflammatory mediators that increase their secretion (Smith, 2009).

Polypnea was evident in most cases of pneumonic calves and could be attributed to the short term compensatory mechanism of hypoxemia and hypercapnia resulting from respiratory disease as hypoxemia and or hypercapnia stimulate the respiratory centre in the medulla oblongata causing an increase in the minute volume, which mediated by increase tidal volume and frequency of respiration as stated by (Andrews et al., 2004).

Coughing was evident in some cases of diseased calves that become spontaneous induced single as in upper respiratory tract disorders and spontaneous paroxysmal as in the pneumonic cases. Coughing is initiated by reflex stimulation of the cough centre in the medulla oblongata by irritation of sensory receptors that present in the larynx and distal air way by exudates or foreign particles (Robinson et al., 2003).

Exaggerated tracheal sound was reported in early stage of inflammation while rattling and stenotic sound was observed in advanced stage in many cases. Rattling sound occur due to accumulation of the exudates in the lumen of trachea while stenotic sound indicates narrow lumen (Constable et al., 2016). Abnormal lung sounds were evident in diseased cases, which varied according to severity and stage of pulmonary disease that were exaggerated vesicular sound, crackles and wheezes. Exaggerated vesicular sound could be attributed to pulmonary congestion and early stage of inflammation while crackles could be attributed to the increased bronchial exudation, Also the presence of wheezes indicates bronchiolitis, stenosis of the airway by exudates as well 
as pneumonia (Andrews et al., 2004). Similar finding of elevated temperature, cough, nasal discharge and abnormal lung sounds were recorded in pneumonic calves (El-Sheikh et al 2013, A).

Clinical respiratory score and ultras ound scoring:

The clinical respiratory score (CRS) was recorded for diseased calves as shown in table (4). There was a highly significant increase in the mean values of CRS in the cases of BRD in comparison with the control one. In addition to a significant change in upper and lower respiratory tract disorders in comparison with the control healthy group table (5). The recorded clinical respiratory score was in agreement with that previously reported by (McGuirk, 2008) who mentioned that the CRS is coped with the severity of the respiratory diseases and high score indicate more severe condition.

Ollivett and Buczinski, (2016) categorized BRD affected calves on the basis of CRS and TUS into subtypes, including upper respiratory tract infections and clinical pneumonia. In this context, upper respiratory infection is defined as a positive respiratory score and a normal TUS and clinical pneumonia is defined by a positive respiratory score and abnormal TUS, also the authors added that thoracic ultrasound scoring system able to recognize the difference between aerated lung, aerated lung with diffuse pleural roughening (also called comet tail artifact), lobular lung lesions (also called lobular consolidations or lobular pneumonia), and lobar lung lesions (also called lobar consolidations or lobar pneumonia).

A significant increase in the mean values of TUS at $(\mathrm{P} \leq$ 0.05) was recorded in calves suffered from lower respiratory tract disorders (lobar pneumonia, lobular pneumonia, mixed pneumonia and lung abscess) compared with the control group and upper respiratory tract disorders as shown in table (6) this could be attributed to that in case of pneumonia the cellular infiltrates and cellular debris effectively displaces air from the lung tissue, resulting in nonaerated and/or consolidated lung lesions. These lesions change the ultrasonographic character of the lung from that of a strong reflector with reverberation artifact to a homogeneous, hypo echoic structure similar to that of the liver (Caswell and Williams, 2007).

References

Abd El-latif, M.M. (2011). Some bacteriological studies on respiratory affections in calves 
among buffalo farm in Dakahlia governorate. Assiut Vet. Med. J. Vol. 57 No (129): 201-213.

Andrews, A. H., B lowy, R.W., Boyd, H., Eddy, R.G. (2004). Bovine medicine: diseases and husbandry of cattle (second edition), chapter 17, Blackwell science. pp: 239-242.

Buczinski, S., Forté, G., \& Bélanger, A. M. (2013). Ultrasonographic assessment of the thorax as a fast technique to assess pulmonary lesions in dairy calves with bovine respiratory disease. Journal of dairy science, 96(7), 4523-4528.

Buczinski， S., Forté, G., Francoz, D., \& Bélanger, A. M. (2014). Comparison of thoracic auscultation, clinical score, and ultrasonography as indicators of bovine respiratory disease in preweaned dairy calves. Journal of veterinary internal medicine, 28(1), 234-242.

Caswell JL, Williams K. Respiratory systems. In: Maxie MG, editor. Jubb, Kennedy, and Palmer's Pathology of domestic animals. 5th edition. Edinburgh (United Kingdom): Elsevier; 2007. p. 523-655.

Constable, P. D., Hinchcliff, K. W., Done, S. H., \& Grünberg, W. (2016). Veterinary medicinee-book: a textbook of the diseases of cattle, horses, sheep, pigs and goats. Elsevier Health Sciences.
Cramer, M. C., \& Ollivett, T. L. (2019). Growth of preweaned, group-housed dairy calves diagnosed with respiratory disease using clinical respiratory scoring and thoracic ultrasound-A cohort study. Journal of dairy science, 102 (5), 4322-4331

El-Sheikh A, Attai $H$ and Selim H (2020, B). Textbook of Animal Internal Medicine, ETC Printers, Ismailia, Egypt.

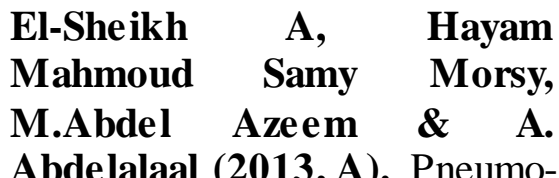
enteritis problems in dairy cattle (Diagnosis, treatment \& field study). Egyptian Journal of Applied Sciences (ISSN 11101571) volume 28 No 6 Page 193199

Glove r, I. D. (2017). Improving calf-side diagnosis of respiratory disease on UK dairy farms. Livestock, 22(5), 230238.

Griffin, D., Chengappa, M.M., Kuszak, J., \& McVey, D. S. (2010). Bacterial pathogens of the bovine respiratory disease complex. Veterinary Clinics: Food Animal Practice, 26(2), 381-394.

Hägglund, S., Svensson, C., Emanuelson, U., Valarcher, J.F. and Alenius, S. (2006) : Dynamics of virus infections involved in the bovine 
respiratory disease complex in Swedish dairy herds. Vet. J. Vol. 172. No (2): 320-328.

Love, W. J., Lehenbauer, T. W., Kass, P. H., Van Eenennaam, A. L., \& Aly, S. S. (2014). Development of a novel clinical scoring system for onfarm diagnosis of bovine respiratory disease in preweaned dairy calves. PeerJ, 2, e238.

McGuirk, S.M. (2008). Disease management of dairy calves and heifers. Vet. Clin. North Am. Food Anim. Pract. Vol. 24:139153.

Nagy, O., Seidel, H., Paulikova, I., Mudron, P. and Kovac, G. (2006). Use of blood gas and lactic acid analysis in diagnosis and prognosis of respiratory diseases in calves. Bull. Vet. Inst. Pulawy. Vol. 50: 149-152.
Ollivett, T. L., \& Buczinski, S. (2016). On-farm use of ultrasonography for bovine respiratory disease. Veterinary Clinics: Food Animal Practice, 32(1), 19-35.

Orro, T. (2008). Acute phase proteins in dairy calves and reindeer: Changes after birth and in respiratory infections.

Robinson, N. E., Berney, C., Eberhart, S., deFeịter-Rupp, H. L., Jefcoat, A. M., Cornelisse, C. J.,...\& \& Derksen, F. J. (2003). Coughing, mucus accumulation, airway obstruction, and airway inflammation in control horses and horses affected with recurrent airway obstruction. American journal of veterinary research, 64(5), 550557.

Smith, B.P. (2015). Large Animal Internal Medicine, $5^{\text {th }}$. ed. Mosby Elsevier. 